\title{
Pterional variable topography and morphology. An anatomical study and its clinical significance
}

\author{
K. Natsis ${ }^{1}$, I. Antonopoulos², C. Politis ${ }^{3,4}$, E. Nikolopoulou², N. Lazaridis', G.P. Skandalakis², \\ D. Chytas 5 , M. Piagkou²
}

\author{
${ }^{1}$ Department of Anatomy and Surgical Anatomy, School of Medicine, Faculty of Health Sciences, \\ Aristotle University of Thessaloniki, Greece \\ 2Department of Anatomy, School of Medicine, Faculty of Health Sciences, National and \\ Kapodistrian University of Athens, Greece \\ ${ }^{3}$ OMFS-IMPATH Research Group, Department of Imaging and Pathology, Faculty of Medicine, \\ Katholieke Universiteit Leuven, Belgium \\ ${ }^{4}$ Department of Oral and Maxillofacial Surgery, University Hospitals Leuven, Belgium \\ ${ }^{5}$ School of Medicine, European University of Cyprus, Engomi, Nicosia, Cyprus
}

[Received: 6 July 2020; Accepted: 27 July 2020; Early publication date: 3 September 2020]

\begin{abstract}
Background: Pterion is the junction of the frontal, parietal, greater wing of the sphenoid and the squamous part of the temporal bone. The sphenoparietal, frontotemporal, stellate and epipteric pteria were described. The current study determines pterion topography, morphology (variant types' frequency) and morphometry, as well as epipteric bones presence in dried skulls. Gender impact is underlined as well.

Materials and methods: Ninety Greek adult dried skulls were observed. The distances in between pterion and the zygomatic arch midpoint and in between pterion and the frontozygomatic suture were measured.

Results: The sphenoparietal pterion was the commonest (58.3\%), following by the stellate (25\%), epipteric (15.5\%) and by the frontotemporal pterion (1.1\%). Twenty-eight (15.5\%) skulls had epipteric bones, further categorised as quadrisutural (35.7\%), trisutural (57.1\%), bisutural and multiple (3.57\%). The mean distances between pterion and the midpoint of zygomatic arch were $4.13 \pm 0.45 \mathrm{~cm}$ on the right and $4.09 \pm 0.47 \mathrm{~cm}$ on the left side and between pterion and the frontozygomatic suture were $3.47 \pm 0.61 \mathrm{~cm}$ on the right and $3.52 \pm 0.65 \mathrm{~cm}$ on the left side. Both distances were symmetrical. Male skulls showed slightly higher values on the left side for the distance (pterion-midpoint of zygomatic arch).

Conclusions: Pterion is a commonly used neurosurgical landmark and thus in depth knowledge of the pteric area and its variants could be valuable. Recognition of the possible variability in pterion location, morphology and morphometry, as well as possible occurrence of epipteric bones may render pterional craniotomy safer among different population groups. (Folia Morphol 2021; 80, 4: 994-1004)
\end{abstract}

Key words: pterion, skull, zygomatic arch, frontozygomatic suture, epipteric bone, variation, anatomy

Address for correspondence: Assoc. Prof. M. Piagkou, DDS, MD, MSc, PhD, Department of Anatomy, School of Medicine, Faculty of Health Sciences, National and Kapodistrian University of Athens, M. Asias 75, Street, 11527 Greece, tel: +30 210 7462427, fax: +30 210 7462398, Mob: +306984316353, e-mail: mapian@med.uoa.gr; piagkoumara@gmail.com

This article is available in open access under Creative Common Attribution-Non-Commercial-No Derivatives 4.0 International (CC BY-NC-ND 4.0) license, allowing to download articles and share them with others as long as they credit the authors and the publisher, but without permission to change them in any way or use them commercially. 


\section{INTRODUCTION}

Pterion, an $\mathrm{H}$-shaped small circular area, is a point of convergence of the frontal $(F)$, sphenoid $(S)$, parietal $(P)$, and squamous part of the temporal bone (T) (articulation of the coronal, sphenoparietal, squamosal, sphenofrontal and sphenosquamosal sutures) $[36,56]$. It corresponds to the site of the anterolateral (sphenoidal) fontanelle which disappears approximately 3 months after birth [50]. Although the sutures contributing to pterion, exhibit a wide variability [11], their relationships are not yet elucidated. Variant sutural patterns in pterional area are the outcome of combination of various environmental and epigenetic factors [7, 55].

From the morphometric point of view, as the classical anatomical textbooks refer, the pterion is located approximately $3.0-3.5 \mathrm{~cm}$ behind the frontozygomatic suture (FZMS) and $4.0 \mathrm{~cm}$ above the midpoint of the zygomatic arch (MPZ) forming the temporal fossa floor [36, 50].

Pterion is a reference cranial landmark for the anterior branch of the middle meningeal artery, the Broca's motor speech area, the insula, the stem of lateral sulcus and the anterior cisterns of the encephalon base $[14,16,23,40]$. In addition, age and gender determination in forensic and archaeological cases could be based on pterion [29].

Although suboptimal pterion localisation may compromise surgical access and therefore treatment outcome, studies focusing on pterion morphology and surgical anatomy are scarce. Knowledge of pterion location, presence and distribution of sutural bones convergence, the so-called epipteric bones (EBs), as well as different types of classified pteria are important to prevent complications when drilling burr pterional holes [24, 46]. In such cases, (i.e. in a penetrating orbital injury) surgery should be minimally invasive, while gaining access to the sphenoid ridge and optic canal [59].

The current study underlines morphological variability of the bones forming pterional area, taking into consideration variant distribution of EBs, their frequency and relationship with pterion sutures. A terminology of the EBs is proposed. Exact pterion location in relation to FZMS and MPZ was also recorded. Both morphological and morphometric observations were analysed taking into account laterality, gender and age as well.

\section{MATERIALS AND METHODS}

Ninety (49 male and 41 female) Greek adult dried skulls from the osseous collections of the Department of Anatomy and Surgical Anatomy of the Aristotle University and the Department of Anatomy of the National and Kapodistrian University were investigated on the right ( $\mathrm{R}$ ) and left ( $\mathrm{L}$ ) sides (180 sides). Exclusion criteria included children skulls, unknown gender and age skulls, damaged and deformed skulls and skulls with pathology and trauma affecting measurement landmarks. Thus, 180 (98 male and 82 female) pteria were subdivided in three age groups: 20-39 years (46 pteria), 40-59 years (40 pteria), over 60 years of age (94 pteria) to examine age effect in pterion topography, morphology and morphometry. All skulls were derived from body donation, before death, after written informed consent.

Pterion morphology. Various pteria frequencies were recorded and all pteria were classified into four types, based on Murphy's classification [37]. Sphenoparietal (SP), frontotemporal (FT), stellate (St) and epipteric (E) pteria appear in Figure $1 A, B, C$, and $D$, respectively. A circle was drawn to locate the adjacent bones forming pterion area.

Epipteric bones number and distribution. Skulls with $E$ pterion (EBs) were further classified having as a guide the number of sutures converging to the EB. A novel epipteric terminology, based on the number and name (frontal $-\mathrm{F}$, parietal $-\mathrm{P}$, temporal $-\mathrm{T}$, and sphenoidal $-S$ ) of sutures articulating with $E B$, is proposed:

- single EB articulating with 4 sutures (FPTS) (a typical quadrisutural EB) (Fig. 2A);

- a single EB articulating with 3 sutures (trisutural EB) was further subclassified as superior (FPT) (Fig. 3A), inferior (FTS) (Fig. 3B), anterior (FPS) (Fig. 3C), and posterior (PTS) (Fig. 3D);

- an EB articulating with two sutures (PS or ST) (bisutural EB) (Fig. 2B);

- several EBs or multiple (in the form of multiple fragments) (Fig. 2C).

Pterion morphometry. Two distances, in between pterion centre and MPZ and pterion centre and FZMS were bilaterally measured using a digital calliper (Mitutoyo, ABSOLUTE 500-196-20 Digital Calliper, $0.001 \mathrm{~mm}$ accuracy) (Fig. 4). The study was conducted in accordance to the Ethical Committee standards and with the 1964 Helsinki declaration and its later amendments. Measurements' reliability was assessed by examining the interobserver and intraobserver reliabilities using interclass and intraclass correlation coefficient. The intraclass correlation coefficient (ICC) was interpreted as poor if it 


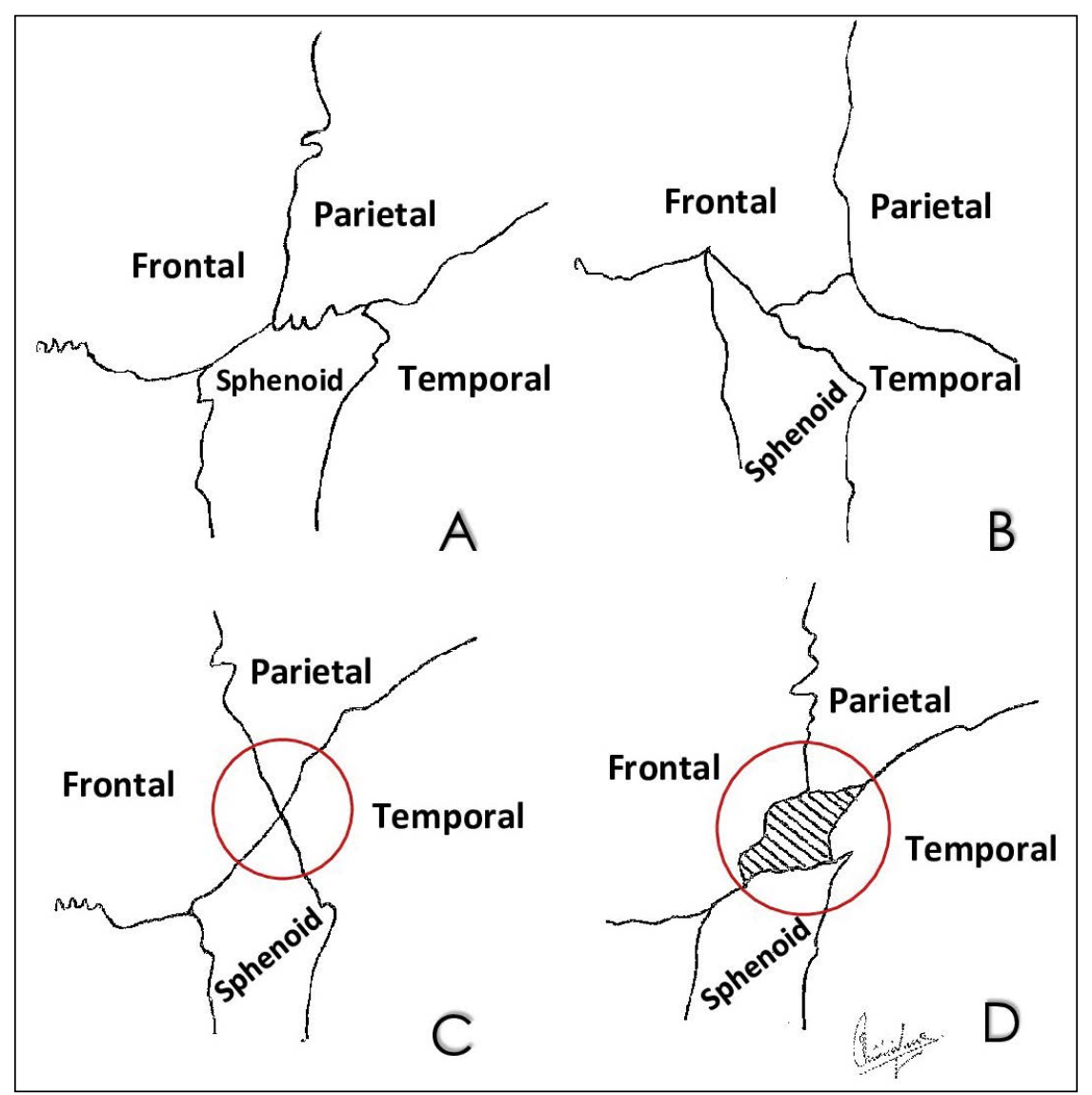

Figure 1. The frequency of various types of pterion based on Murphy's classification as modified accordingly, sphenoparietal (A), frontotemporal (B), stellate (C), and epipteric (D).

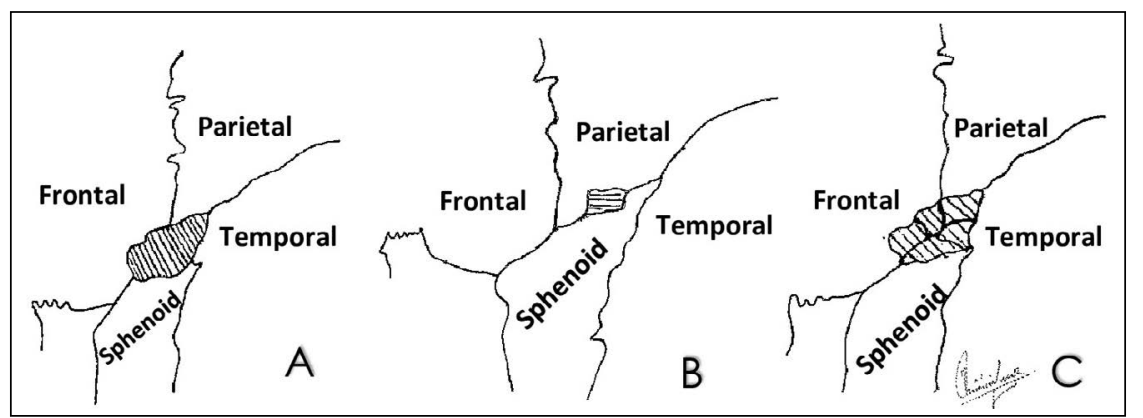

Figure 2. Classification of epipteric bones as quadrisutural (A), bisutural (B) and multiple (C).

was less than 0.4 ; as marginal when it was between 0.4 and 0.75 ; and as good when it was greater than 0.75 . Descriptive statistics were evaluated for pterion morphometric measurements and their statistical distribution was analysed. Data normality was evaluated with Kolmogorov-Smirnov test. Wilcoxon signed ranks test was applied to investigate side asymmetry, Mann-Whitney $U$ test and t test for gender dimorphism, and Kruskal-Wallis and one-way ANOVA tests to evaluate correlation with age. For all analyses, $p$ value $<0.05$ was consid- ered statistically significant. Statistical analysis was carried out using IBM SPSS Statistics for Windows, version 21.0.

\section{RESULTS}

Pterion morphology. All pteria types (SP, FT, St and E) were identified (Fig. 5). SP pterion was the predominant type $(58.3 \%, 105$ skulls), St the second most common ( $25 \%, 45$ skulls) following by the $E$ (15.5\%, 28 skulls) and the FT type (1.1\%, 2 skulls on the R). Pterional symmetry was detected (57 skulls, 


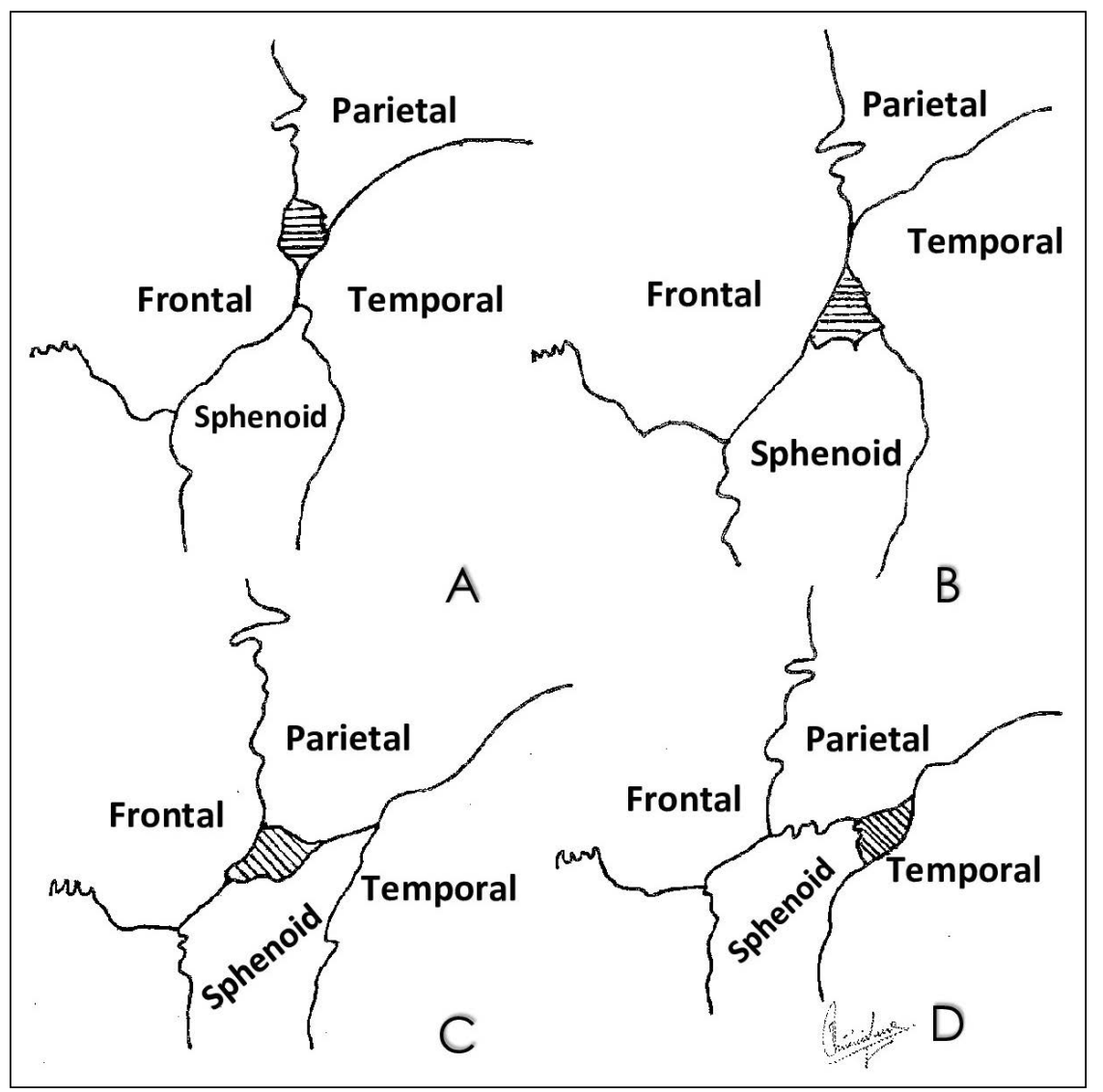

Figure 3. Classification of the trisutural epipteric bones observed according to their location as superior (A), inferior (B), anterior (C) and posterior (D).

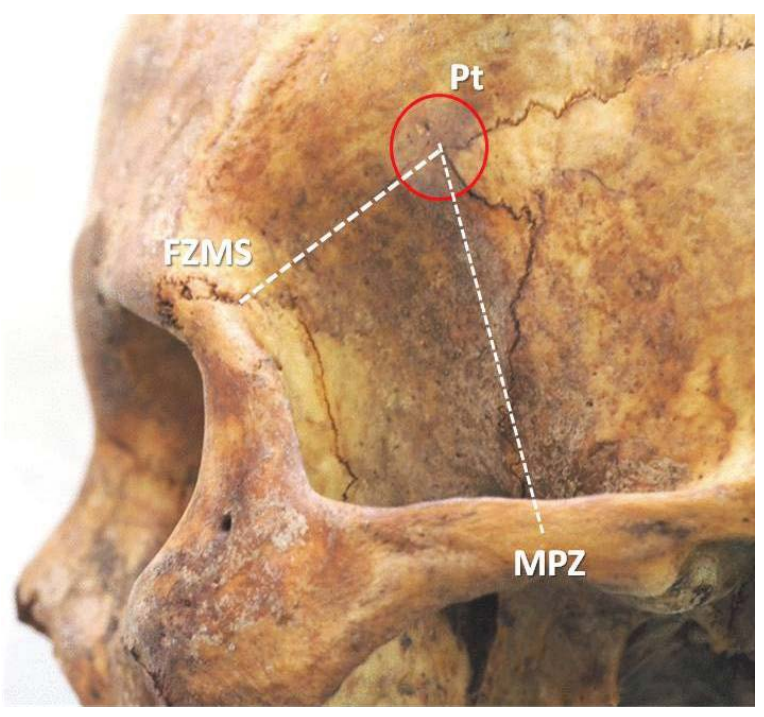

Figure 4. Distances from the pterion $(\mathrm{Pt})$ centre to the midpoint of zygoma (MPZ) and from the Pt centre to the frontozygomatic suture (FZMS).

63.3\%) (SP in 43 , St in 10 and $E$ in 4 skulls). In asymmetrically pairing skulls, the commonest pterion types were the SP-St $(16.7 \%, 15$ skulls) and the SP-E
(12 skulls). Age and gender had no significant impact on pterion type (Table 1).

Epipteric bone morphology. Twenty-eight (15.5\%) skulls with EBs were further classified as quadrisutural (FPTS) (Fig. 6A) (35.7\%, 10 skulls, 1 skull bilaterally and 9 skulls unilaterally $-5 \mathrm{~L}$ and $4 \mathrm{R})$, trisutural (Fig. 6B) (57.1\%, 16 skulls unilaterally $-11 \mathrm{~L}$ and $5 \mathrm{R}$ ), bisutural (3.57\%, 1 skull on the L) (Fig. 6C) and multiple EBs (3.57\%, 1 skull on the L) (Fig. 6D).

Pterion morphometry. The mean distances (pterion-MPZ) and (pterion-FZMS) were symmetrical (R: $4.13 \pm 0.45 \mathrm{~cm}, \mathrm{~L}: 4.09 \pm 0.47 \mathrm{~cm}$ ) and (R: $3.47 \pm$ $\pm 0.61 \mathrm{~cm}, \mathrm{~L}: 3.52 \pm 0.65 \mathrm{~cm})$. No gender dimorphism was detected for all measured distances, except for the mean distance (pterion-FZMS) on the $L$ (males $3.65 \pm 0.72$ vs. females $3.37 \pm 0.51 \mathrm{~cm}, p=0.039$ ) (Table 2). No statistically significant difference was detected for both measurements among different age groups (Table 3). ICC for the interobserver and intraobserver reliabilities was 0.892 and 0.901 for pterion-MPZR, 0.879 and 0.845 for pterion-MPZL, 0.908 and 0.897 for pterion-FZMSR and 0.867 and 0.856 for pterion-FZMSL, respectively. 

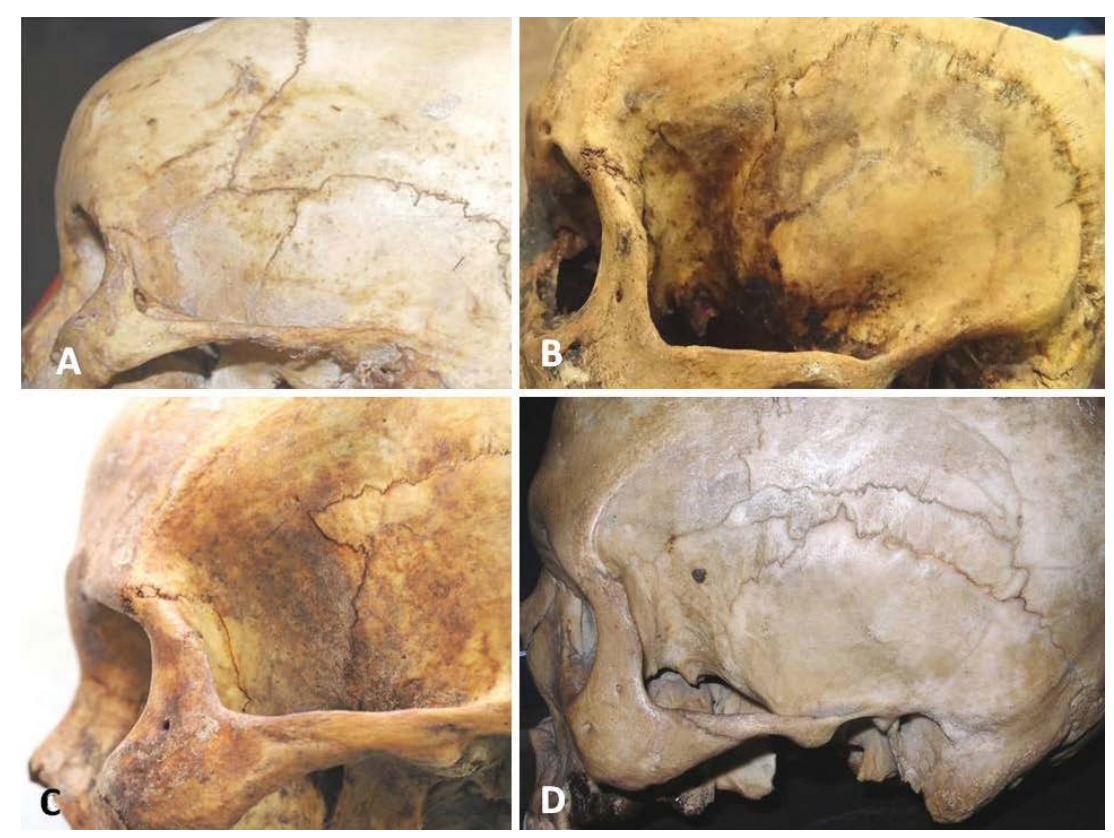

Figure 5. Depiction of various pterion types in Greek skulls, sphenoparietal (A), frontotemporal (B), stellate (C), and epipteric (D).

Table 1. Pterion types' frequency observed on the right (R) and left (L) sides of the skulls, combination types on asymmetrical skulls, gender ( $\mathrm{M}$ - males, $\mathrm{F}$ - females) and age impact

\begin{tabular}{|c|c|c|c|c|c|c|c|c|c|}
\hline \multirow{2}{*}{$\begin{array}{l}\text { Independent } \\
\text { variables }\end{array}$} & \multicolumn{8}{|c|}{ Pterion types } & \\
\hline & \multirow{2}{*}{\multicolumn{2}{|c|}{ Sphenoparietal type (SP) }} & \multirow{2}{*}{\multicolumn{2}{|c|}{ Frontotemporal type (FT) }} & \multirow{2}{*}{\multicolumn{2}{|c|}{ Epipteric type (E) }} & \multirow{2}{*}{\multicolumn{2}{|c|}{ Stellate type (S) }} & \\
\hline \multicolumn{2}{|l|}{ Laterality } & & & & & & & & \\
\hline Right side (R) & \multicolumn{2}{|c|}{$50(55.5 \%)$} & \multicolumn{2}{|c|}{$2(2.2 \%)$} & \multicolumn{2}{|c|}{$11(12.2 \%)$} & \multicolumn{2}{|c|}{$27(30 \%)$} & \\
\hline Left side (L) & \multicolumn{2}{|c|}{$55(61.1 \%)$} & \multicolumn{2}{|c|}{-} & \multicolumn{2}{|c|}{$17(18.9 \%)$} & \multicolumn{2}{|c|}{$18(20 \%)$} & \\
\hline Total & \multicolumn{2}{|c|}{$105(58.3 \%)$} & \multicolumn{2}{|c|}{$2(1.1 \%)$} & \multicolumn{2}{|c|}{$28(15.5 \%)$} & \multicolumn{2}{|c|}{$45(25 \%)$} & \\
\hline \multicolumn{10}{|c|}{ Combination types of pterion } \\
\hline SP-SP & \multicolumn{2}{|c|}{ SP-S } & \multicolumn{2}{|c|}{ SP-E } & \multicolumn{2}{|c|}{ S-S } & \multicolumn{2}{|c|}{ E-E, SP-FT } & E-S \\
\hline $43(47.8 \%)$ & \multicolumn{2}{|c|}{$15(16.7 \%)$} & \multicolumn{2}{|c|}{$12(13.3 \%)$} & \multicolumn{2}{|c|}{$10(11.1 \%)$} & \multicolumn{2}{|c|}{$4(4.44 \%)$} & $2(2.22 \%)$ \\
\hline \multirow[t]{2}{*}{ Gender } & \multicolumn{2}{|c|}{ Type SP } & \multicolumn{2}{|c|}{ Type FT } & \multicolumn{2}{|c|}{ Type E } & \multicolumn{2}{|c|}{ Type S } & $\mathbf{P}$ \\
\hline & $\mathbf{R}$ & $\mathbf{L}$ & $\mathbf{R}$ & $\mathbf{L}$ & $\mathbf{R}$ & $\mathbf{L}$ & $\mathbf{R}$ & $\mathbf{L}$ & \\
\hline Males & $30(61.2 \%)$ & $31(63.26 \%)$ & $1(2.04 \%)$ & - & $2(4.08 \%)$ & $10(20.4 \%)$ & $16(32.65 \%)$ & $8(16.32 \%)$ & \multirow{3}{*}{$\begin{array}{l}0.187 \\
0.829\end{array}$} \\
\hline Females & $20(48.78 \%)$ & $24(58.53 \%)$ & $1(2.43 \%)$ & - & $9(21.95 \%)$ & $7(17.07 \%)$ & $11(26.82 \%)$ & $10(24.39 \%)$ & \\
\hline Total & 61 sides in $\mathrm{M}$ & I, 44 sides in $\mathrm{F}$ & 1 side in $I$ & ide in $\mathrm{F}$ & 12 sides in $\mathrm{N}$ & 16 sides in $\mathrm{F}$ & 24 sides in $M$ & 21 sides in $\mathrm{F}$ & \\
\hline
\end{tabular}

\section{DISCUSSION}

Pterion morphology. Pterion variable morphology is classified into SP, FT, St and E types and has been extensively studied among different populations (Table 4). In depth knowledge of pterion type and location could be an extremely useful tool in neurosurgical procedures, skull identification and forensics. Yasargil et al. (1975) [58] first introduced the pterional approach and its extension. Pterional approach achieves more accurate and safer outcomes for sellar or suprasellar lesions, brain arterial circula- tion and lateral sulcus, as well as for aneurysms of the distal internal carotid artery, as the conventional craniotomy was replaced from mini-craniotomy and to contemporary keyhole surgery [12].

Although classical anatomical textbooks describe $\mathrm{St}$ pterion as the typical pattern, this pterion was found with a frequency of $25 \%$ in the current study, while the predominant pterion was the SP (58.3\%), similarly to all the other studies summarized in Table 4. In Asians, the SP pterion frequency ranged between $71.7 \%$ and $93.55 \%$ and among them Indians have the highest fre- 

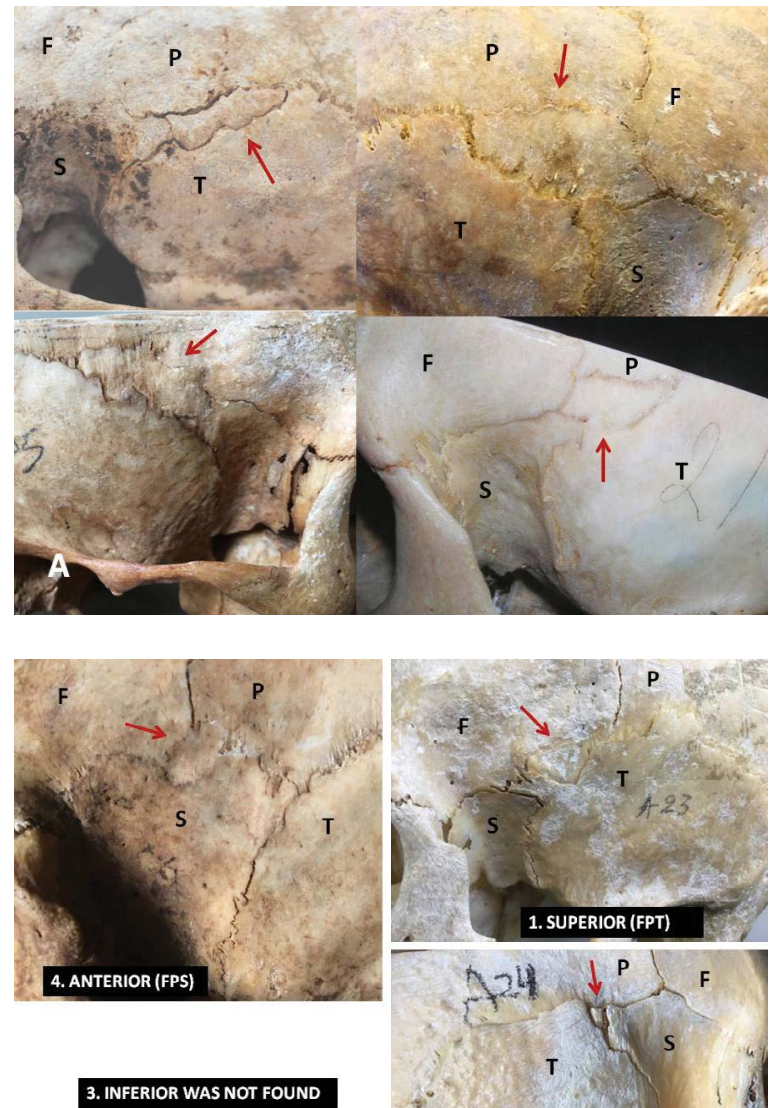

B

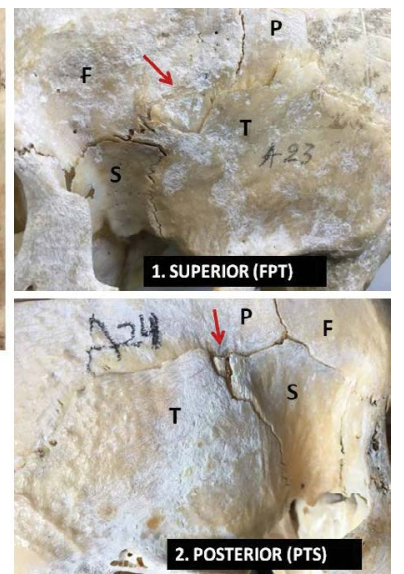

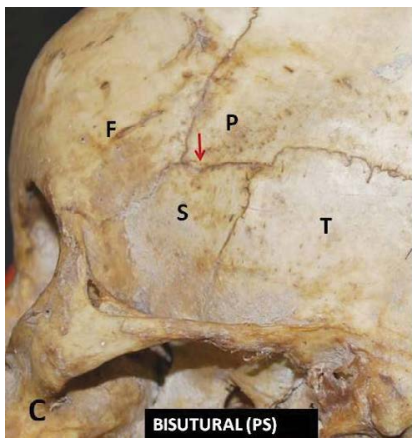
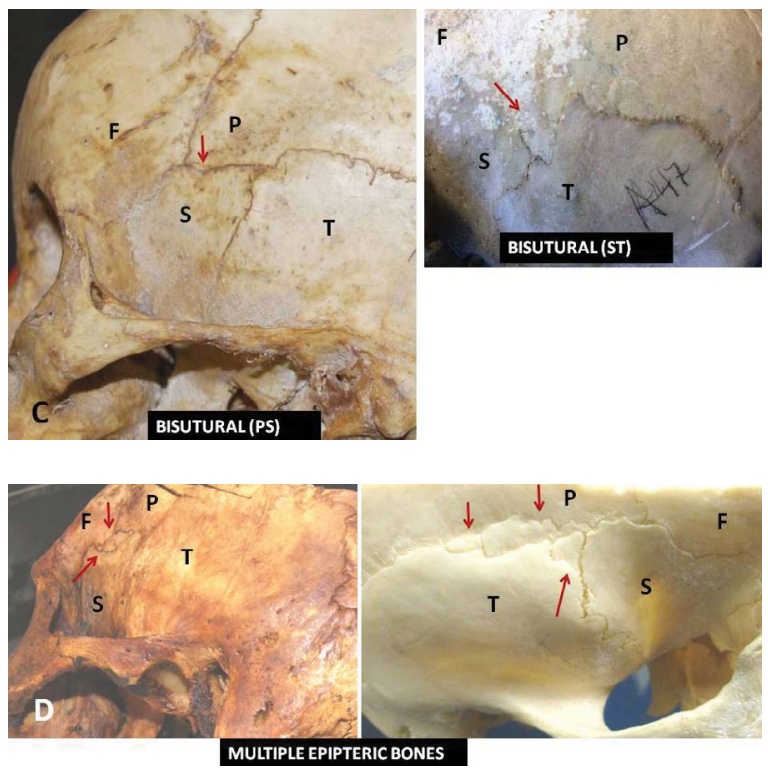

Figure 6. A. Quadrisutural epipteric bones (red arrow); F - frontal bone; $\mathrm{P}$ - parietal bone; $\mathrm{S}$ - sphenoid bone; $\mathrm{T}$ - temporal bone; B. Trisutural epipteric bones according to their location (superior -1 , posterior -2 , inferior -3 [not found] and anterior -4 ); C. Bisutural epipteric bones in between parietal and sphenoid bones (PS) as well as in between sphenoid and temporal bones (ST); D. Multiple epipteric bones depicted with red arrows.

Table 2. Mean \pm standard deviation (SD), minimum and maximum distances of pterion (Pt) to the midpoint of zygoma (MPZ) and to the frontozygomatic suture (FZMS) [cm] on the right (R) and left $(\mathrm{L})$ sides of the skulls, male and female incidence

\begin{tabular}{|c|c|c|c|c|c|c|c|c|c|c|c|c|}
\hline \multirow[t]{3}{*}{ Values } & \multirow{2}{*}{\multicolumn{4}{|c|}{ Distances according to side }} & \multicolumn{8}{|c|}{ Distances according to gender } \\
\hline & & & & & \multicolumn{2}{|c|}{ Males } & \multicolumn{2}{|c|}{ Females } & \multicolumn{2}{|c|}{ Males } & \multicolumn{2}{|c|}{ Females } \\
\hline & $\begin{array}{l}\text { Pt-MPZ } \\
\text { R }\end{array}$ & $\begin{array}{c}\text { Pt-MPZ } \\
\text { L }\end{array}$ & $\begin{array}{l}\text { Pt-FZMS } \\
\text { R }\end{array}$ & $\begin{array}{c}\text { Pt-FZMS } \\
\text { L }\end{array}$ & $\begin{array}{l}\text { Pt-MPZ } \\
\text { R }\end{array}$ & $\begin{array}{c}\text { Pt-MPZ } \\
\text { L }\end{array}$ & $\begin{array}{l}\text { Pt-MPZ } \\
\text { R }\end{array}$ & $\begin{array}{l}\text { Pt-MPZ } \\
\quad \text { L }\end{array}$ & $\begin{array}{c}\text { Pt-FZMS } \\
\text { R }\end{array}$ & $\begin{array}{c}\text { Pt-FZMS } \\
\text { L }\end{array}$ & $\begin{array}{l}\text { Pt-FZMS } \\
\text { R }\end{array}$ & $\begin{array}{c}\text { Pt-FZMS } \\
\quad \text { L }\end{array}$ \\
\hline Mean \pm SD & $\begin{array}{l}4.13 \pm \\
0.45\end{array}$ & $4.1 \pm 0.47$ & $\begin{array}{c}3.47 \pm \\
0.61\end{array}$ & $\begin{array}{c}3.52 \pm \\
0.65\end{array}$ & $\begin{array}{c}4.19 \pm \\
0.44\end{array}$ & $\begin{array}{l}4.12 \pm \\
0.55\end{array}$ & $\begin{array}{c}4.04 \pm \\
0.46\end{array}$ & $\begin{array}{c}4.07 \pm \\
0.42\end{array}$ & $\begin{array}{c}3.51 \pm \\
0.62\end{array}$ & $\begin{array}{c}3.65 \pm \\
0.73\end{array}$ & $\begin{array}{c}3.43 \pm \\
0.59\end{array}$ & $\begin{array}{c}3.37 \pm \\
0.51\end{array}$ \\
\hline Minimum & 2.87 & 3.11 & 2.0 & 1.73 & 3.29 & 3.11 & 2.87 & 3.16 & 2.09 & 1.73 & 2.0 & 2.48 \\
\hline Maximum & 5.32 & 5.7 & 4.81 & 5.2 & 5.32 & 5.7 & 5.2 & 5.1 & 4.63 & 5.2 & 4.81 & 4.78 \\
\hline$P$ & \multicolumn{2}{|c|}{$\begin{array}{l}p=0.608 \\
\text { (symmetry) }\end{array}$} & \multicolumn{2}{|c|}{$\begin{array}{l}p=0.471 \\
\text { (symmetry) }\end{array}$} & \multicolumn{4}{|c|}{$\begin{array}{c}p=0.133 \text { right ANOVA, } \\
p=0.619 \text { left ANOVA }\end{array}$} & \multicolumn{4}{|c|}{$\begin{array}{c}\mathrm{p}=0.517 \text { right ANOVA, } \mathrm{p}=0.039 \text { left } \\
\text { (gender dimorphism) }\end{array}$} \\
\hline
\end{tabular}

quencies (69.25-93.5\%) (Southern [80-93.55\%] and Western Indians [91.7\%] showed higher frequencies compared to Northern [71.7-89.2\%]), while Koreans have the lowest (76.5\%) [26]. Kenyans had the lowest reported frequency (66\%) [38]. The high frequency of SP pterion could be a result of evolution [28], given that it is the commonest type in primates $[8,47]$.

The second commonest pterion type is the FT [54], with a varying incidence among different populations:
Nigerians (10.1\% and $23.6 \%$ ) [46], Northern Indians (10\%) [62], Turkish (10\%) [40] and Kenyans 15\% [38]. In the current study, the frequency of FT pterion was significantly lower ( $2.2 \%$ on the $\mathrm{R})$, whereas no skull was found with a FT pterion on the L. However, the frequency is similar to those of Indian (Western [31] and Southern [36]) populations. In the present study, St pterion was the second most common type on the $R(30 \%)$ and $L(20 \%)$. The frequency of the $E$ type of 
Table 3. Mean values standard deviation (SD), minimum and maximum distances (in $\mathrm{cm}$ ) from the pterion to the midpoint of zygoma (MPZ) and to the frontozygomatic suture (FZMS) on the right (R) and left (L) sides of the skulls among the three age groups

\begin{tabular}{|c|c|c|c|c|c|c|c|c|c|c|c|c|}
\hline \multirow[t]{3}{*}{$\mathbf{N}$} & \multicolumn{12}{|c|}{ Age groups [years] } \\
\hline & \multicolumn{4}{|c|}{$20-39$} & \multicolumn{4}{|c|}{$40-59$} & \multicolumn{4}{|c|}{ Over 60} \\
\hline & MPZ R & MPZL & FZMS R & FZMS L & MPZ R & MPZL & FZMS R & FZMS L & MPZ R & MPZL & FZMS R & FZMS L \\
\hline $\begin{array}{l}\text { Mean } \pm \\
\text { SD }\end{array}$ & $\begin{array}{c}4.15 \pm \\
0.43\end{array}$ & $\begin{array}{c}4.12 \pm \\
0.44\end{array}$ & $\begin{array}{c}3.40 \pm \\
0.7\end{array}$ & $\begin{array}{c}3.37 \pm \\
0.75\end{array}$ & $\begin{array}{c}4.1 \pm \\
0.45\end{array}$ & $\begin{array}{c}4.1 \pm \\
0.5\end{array}$ & $\begin{array}{c}3.38 \pm \\
0.66\end{array}$ & $\begin{array}{c}3.46 \pm \\
0.71\end{array}$ & $\begin{array}{c}4.13 \pm \\
0.48\end{array}$ & $\begin{array}{c}4.1 \pm \\
0.48\end{array}$ & $\begin{array}{c}3.54 \pm \\
0.53\end{array}$ & $\begin{array}{c}3.62 \pm \\
0.56\end{array}$ \\
\hline Minimum & 3.51 & 3.44 & 2.0 & 2.25 & 3.29 & 3.11 & 2.09 & 1.73 & 2.87 & 3.16 & 2.3 & 2.4 \\
\hline Maximum & 5.2 & 5.1 & 4.81 & 4.69 & 4.73 & 4.93 & 4.32 & 4.90 & 5.32 & 5.70 & 4.40 & 5.2 \\
\hline$P$ & \multicolumn{12}{|c|}{$p=0.916$ right $M P Z, p=0.522$ right $F Z M S, p=0.962$ left $M P Z$ and $p=0.319$ left FZMS } \\
\hline
\end{tabular}

Table 4. Comparative review of pterion types in different populations among several studies, arranged in order by year of publication

\begin{tabular}{|c|c|c|c|c|c|c|c|}
\hline \multirow[t]{2}{*}{ Author(s) } & \multirow[t]{2}{*}{ Year } & \multirow[t]{2}{*}{ Population } & \multirow{2}{*}{$\begin{array}{c}\text { Sample } \\
\mathrm{N}=\text { skulls (sides) }\end{array}$} & \multicolumn{4}{|c|}{ Type of pterion } \\
\hline & & & & Sphenoparietal (\%) & Frontotemporal (\%) & Stellate (\%) & Epipteric (\%) \\
\hline Murphy [37] & 1956 & Australian & 368 & 73.2 & 7.7 & 0.7 & 18.4 \\
\hline Agarwal et al. [2] & 1980 & North Indian & 450 (900 sides) & 71.7 & 3.3 & 1.7 & 23.3 \\
\hline Saxena et al. [47] & 1988 & Indian & $72(144)$ & 82.6 & 2.8 & 1.4 & 13.2 \\
\hline Saxena et al. [47] & 1988 & Nigerian & $40(80)$ & 81.2 & 11.3 & 5.0 & 2.5 \\
\hline Manjunath and Thomas [31] & 1988 & South Indian & 172 & 93.5 & 3.5 & 2.9 & 17.3 \\
\hline Matsumura et al. [32] & 1991 & Japanese & 614 & 82.4 & 2.9 & 0.7 & 14.0 \\
\hline Asala and Mbajiorgu [7] & 1996 & Nigerian & 212 & 82.1 & 23.6 & - & 5.7 \\
\hline Lee et al. [26] & 2001 & Korean & 149 & 76.5 & - & - & 40.3 \\
\hline Saxena et al. [46] & 2003 & North Indian & 203 & 87.7 & 10.0 & 5.17 & - \\
\hline Ersoy et al. [14] & 2003 & Turkish & 300 (490 sides) & 96.0 & 3.8 & 0.2 & 9.0 \\
\hline Oguz et al. [40] & 2004 & Turkish & $26(52)$ & 88.0 & 10.0 & - & 2.0 \\
\hline Mwachaka et al. [38] & 2009 & Kenyan & 50 & 66.0 & 15.0 & 7.0 & 12.0 \\
\hline Illknur et al. [22] & 2009 & Anatolian & 28 & 89.2 & 3.6 & 3.6 & 3.6 \\
\hline Zalawadia et al. [62] & 2009 & West. Indian & 42 & 91.7 & 2.4 & 1.2 & 4.7 \\
\hline Hussain Saheb et al. [20] & 2010 & Indian & 125 & 69.25 & 17.35 & 9.7 & 3.7 \\
\hline Apinhasmit et al. [6] & 2011 & Thais & $268(536)$ & 81.2 & 1.1 & 0.4 & 17.3 \\
\hline Natekar et al. [39] & 2011 & Indian & 150 bones & 85.3 & 8.0 & 10.6 & 51.4 \\
\hline Ma et al. [30] & 2012 & Australian & 76 & 78.4 & 5.2 & - & 16.4 \\
\hline $\begin{array}{l}\text { Praba and } \\
\text { Venkatramaniah [41] }\end{array}$ & 2012 & Indian & 50 & 74.0 & 3 & 9.0 & 14.0 \\
\hline Ukoha et al. [53] & 2012 & Nigerian & 56 & 75.3 & 19.5 & 1.7 & 3.6 \\
\hline Adejuwon et al. [1] & 2013 & Nigerian & 62 & 86.1 & 8.3 & 5.6 & - \\
\hline Kumar et al. [25] & 2013 & Indian & 40 & 86.25 & 11.25 & 2.5 & - \\
\hline Sudha et al. [51] & 2013 & South Indian & 150 & 80.0 & 3.0 & 5.3 & 11.3 \\
\hline Aksu et al. [3] & 2014 & Anatolian & 128 & 85.2 & 1.1 & 5.5 & 8.2 \\
\hline Eboh and Obaroefe [13] & 2014 & Nigerian & 50 & 83.0 & 5.0 & 6.0 & 6.0 \\
\hline Prasad et al. [42] & 2015 & North Indian & 60 & 89.2 & 3.3 & 5.0 & 2.5 \\
\hline Modasiya and Kanani [35] & 2018 & North Indian & 220 & 81 & - & 10.9 & 8.1 \\
\hline Present study & 2019 & Greek & 90 & 58.4 & 1.1 & 25 & 15.5 \\
\hline
\end{tabular}


Table 5. Comparative review of pterion (Pt) distances from the frontozygomatic suture (FZMS) and the midpoint of zygoma (MPZ) among different populations in several studies, in order by year of publication (in $\mathrm{cm}$ )

\begin{tabular}{lccccccc}
\hline Author(s) & Year & Population & $\begin{array}{c}\text { Sample } \\
\text { N = skulls (sides) }\end{array}$ & Pt-FZMS R & Pt-FZMS L & Pt-MPZ R & Pt-MPZ L \\
\hline Oguz et al. [40] & & & & & & & \multicolumn{4}{c}{ Distances } \\
Ilknur et al. [22] & 2004 & Turkish male & 26 (52) & $3.3 \pm 0.39$ & $3.44 \pm 0.40$ & $4.05 \pm 0.39$ & $3.85 \pm 0.25$ \\
Mwachaka et al. [38] & 2009 & Anatolian & 28 & $3.5 \pm 0.5$ & $3.5 \pm 0.5$ & $3.8 \pm 0.4$ & $3.9 \pm 0.4$ \\
Bhargavi et al. [10] & 2009 & Kenyan & 50 & $3.03 \pm 0.34^{*}$ & $3.03 \pm 0.43^{*}$ & $3.88 \pm 0.35^{*}$ & $3.82 \pm 0.35^{*}$ \\
Ma et al. [30] & 2011 & Indian & 70 & $3.93 \pm 0.37$ & $3.8 \pm 0.40$ & $4.52 \pm 0.32$ & $4.45 \pm 0.35$ \\
Ukoha et al. [53] & 2012 & Australian & 76 & $2.6 \pm 4.0$ & $2.5 \pm 4.0$ & $3.4 \pm 4.0$ & $3.4 \pm 4.0$ \\
Adejuwon et al. [1] & 2012 & Nigerian & 56 & $2.74 \pm 0.07$ & $2.74 \pm 0.06$ & $4.02 \pm 0.05$ & $4.01 \pm 0.03$ \\
Aksu et al. [3] & 2013 & Nigerian & 62 & $3.15 \pm 0.67^{*}$ & $3.08 \pm 0.80^{*}$ & $3.91 \pm 0.58^{*}$ & $3.87 \pm 0.63^{*}$ \\
Eboh and Obavoefe [13] & 2014 & Anatolian & 128 & $3.18 \pm 0.45^{*}$ & $3.14 \pm 0.47^{*}$ & $4.0 \pm 0.40^{*}$ & $3.98 \pm 0.40^{*}$ \\
Present study & 2014 & Nigerian & 50 & $3.21 \pm 0.26^{*}$ & $3.11 \pm 0.22^{*}$ & $4.02 \pm 0.29^{*}$ & $3.95 \pm 0.33^{*}$ \\
\hline
\end{tabular}

${ }^{*}$ Studies with modified measurements into $[\mathrm{cm}]$ from $[\mathrm{mm}] ; \mathrm{L}$ — left; $\mathrm{R}$ — right

Pt is similar to that reported in Indians (11.8\%) [8] and Kenyans (12\%) [38].

Epipteric bone morphology. Ranke (1898) [43] proposed the most suitable hypothesis concerning the EBs occurrence. He supported that an EB appears in case of fusion failure of the postero-superior border of the greater sphenoidal wing (via its separate ossification centre) with the rest part of the greater wing, during the $4^{\text {th }}$ month of the intrauterine life. The EBs occurrence and laterality is variable among different populations, as the result of genetic and epigenetic factors combination $[9,34,45]$. In the current study, among the 28 skulls with EBs (31.1\%), trisutural EBs were found in 16 skulls (17.7\%), quadrisutural in 10 skulls $(11.1 \%)$, bisutural and multiple EBs in a single skull (1.11\%) per each, on the L. Among Indian populations, a wide range of EBs frequency was reported ranging between $2.5 \%$ to $24 \%$ in Northern [42] and Karnataka Indians [5]. Saxena et al. (2003) [46] found the lowest frequency of EBs in Nigerians (3.79\%), contrariwise to the present study reporting the highest frequency of $31.1 \%$. Neurosurgeons should be aware of EBs occurrence and variant distribution, since their presence when making burr holes over the pterional area may lead to complications.

In such cases caution must be made, as the most anterior point of junction of four bones may be mistaken to be the pterion centre resulting in orbital penetration. High index of suspicion is required from both radiologists and neurosurgeons, since in pterional trauma the EBs may be mistaken as a skull fracture in X-rays $[9,62]$.
Pterion morphometry. The mean distances (pterion-MPZ) and (pterion-FZMS) in different populations are summarized in Table 5 . In the present study, the mean (pterion-MPZ) distance was $4.13 \pm 0.45 \mathrm{~cm}$ on the $R$ and $4.09 \pm 0.49 \mathrm{~cm}$ on the $L$, similarly to Nigerian $(4.02 \pm 0.05 \mathrm{~cm}$ on the $R$ and $4.01 \pm 0.03 \mathrm{~cm}$ on the L) [53] and Turkish population $(4.05 \pm 0.39 \mathrm{~cm}$ on the R and $3.85 \pm 0.25 \mathrm{~cm}$ on the L) [40] (4.0 \pm $\pm 0.40 \mathrm{~cm}$ on the $R$ and $3.98 \pm 0.40 \mathrm{~cm}$ on the L) [3] . A lower mean distance has been reported in Australian $(3.4 \pm 4.0 \mathrm{~cm})[30]$ and Anatolian $(3.8 \pm 0.4 \mathrm{~cm})$ populations [22]. However, a higher mean distance has been reported in Indians $(4.52 \pm 0.32 \mathrm{~cm}$ on the $R$ and $4.45 \pm 0.35 \mathrm{~cm}$ on the L) [10].

In the present study, the pterion was detected behind FZMS up to $3.51 \mathrm{~cm}$ in males and up to $3.39 \mathrm{~cm}$ in females. This slight difference may be explained by the larger male skulls. The mean distance (pterion-FZMS) was $3.47 \pm 0.61 \mathrm{~cm}$ on the $R$ and $3.52 \pm$ $\pm 0.65 \mathrm{~cm}$ on the $L$. The highest mean values were reported in Indians [10] ( $3.93 \pm 0.37 \mathrm{~cm}$ on the $R$ and $3.80 \pm 0.40 \mathrm{~cm}$ on the $\mathrm{L}$ ) and the lowest in Australians $(2.6 \pm 4.0 \mathrm{~cm}$ on the $R$ and $2.5 \pm 4.0 \mathrm{~cm}$ on the L) [30] and Nigerians $(2.74 \pm 0.07 \mathrm{~cm}$ on the $R$ and $2.74 \pm$ $\pm 0.06 \mathrm{~cm}$ on the L) [53]. Since significant differences were observed for pterion-MPZ and pterion-FZMS distances among various studies' populations, the pterion topography may vary due to epigenetic, environmental factors and evolution [10, 21, 44].

Pterion could be safely used as a surface landmark in neurosurgical approaches and interventions [40], even in neonates [14]. Its clinical importance derives from the fact that it overlies the anterior (frontal) 
branch of the middle meningeal artery, which is the most frequent source of acute traumatic epidural haematoma [30]. The knowledge of pterional typical anatomy, as well as its variants is important to neurosurgeons during pterional craniotomy [18], especially during extradural haematoma evacuation [49]. If the ophthalmic artery originates from the frontal branch of the middle meningeal artery $[27,48]$, pterional craniotomy could cause ophthalmic artery occlusion, which may end up in blindness [48]. Pterion is also used in various neurosurgical approaches treating anterior and middle skull base lesions [33], such as anterior and posterior cerebral circulation lesions, middle cerebral artery or upper basilar complex aneurysms, optic nerve and sellar and parasellar area lesions, sphenoidal wing, cavernous sinus, orbit, anterior and medial temporal lobe, midbrain, and posterior-inferior frontal lobe tumours, as well as cerebral tumours $[4,12,15,17,19,52,57-61]$.

Information obtained from the current study may be of significant value in preoperative planning and perioperative navigation. Furthermore, recognition of the possible variants in location, morphology and morphometry of the pterion, as well as EBs occurrence may render pterional craniotomy safer among different population groups.

\section{CONCLUSIONS}

All pteria types were found in the current study and SP pterion was the predominant one, while FT was the less frequently observed. Pterional symmetry existed in the majority of cases, while gender and age had no significant impact on pterion type. EBs were observed in $15.5 \%$ of the skulls, and in the majority of the cases were tri- and quatrisutural. The distances of the pterion from MPZ and FZMS were symmetrical and gender dimorphism was found only in pterion-FZMS distance on the L. Information obtained from the current study may be of significant value in preoperative planning and perioperative navigation. Such data are especially mandatory to achieve the optimum craniotomy when neuronavigation is not available. Based on osseous landmarks, the neurosurgeon should be familiar with the sutural junctions, as well as with EBs variants which may be complicate the orientation. Furthermore, recognition of possible variants in pterion location, morphology and morphometry, as well as possible EBs occurrence may render pterional craniotomy safer among different population groups.

\section{Acknowledgements}

The authors wish to thank all those who donated their bodies and tissues for the advancement of education and research. Authors are also grateful to the donors' families.

\section{Conflict of interest: None declared}

\section{REFERENCES}

1. Adejuwon SA, Olopade FE, Bolaji M. Study of the location and morphology of the pterion in adult nigerian skulls. ISRN Anat. 2013; 2013: 403937, doi: 10.5402/2013/403937, indexed in Pubmed: 25938098.

2. Agarwal AK, Singh PJ, Gupta SC, et al. Pterion formation and its vriations in the skulls of Northern India. Anthropol Anz. 1988; 38(4): 265-269.

3. Aksu F, Akyer SP, Kale A, et al. The localization and morphology of pterion in adult West Anatolian skulls. J Craniofac Surg. 2014; 25(4): 1488-1491, doi: 10.1097/ SCS. 0000000000000790 , indexed in Pubmed: 25006922.

4. Al-Mefty O. Supraorbital-pterional approach to skull base lesions. Neurosurgery. 1987; 21(4): 474-477, doi: 10.1227/00006123-198710000-00006, indexed in Pubmed: 3683780.

5. Annam S, Bajpe R. A prospective anatomic study of epipteric bones in dry human skulls of Karnataka. Int J Biomed Adv Res. 2016; 7(6): 262, doi: 10.7439/ijbar. v7i6.3301.

6. Apinhasmit W, Chompoopong S, Chaisuksunt V, et al. Anatomical consideration of pterion and its related references in Thai dry skulls for pterional surgical approach. J Med Assoc Thai. 2011; 94(2): 205-214, indexed in Pubmed: 21534368

7. Asala SA, Mbajiorgu FE. Epigenetic variation in the Nigerian skull: sutural pattern at the pterion. East Afr Med J. 1996; 73(7): 484-486.

8. Ashley-Montagu MF. The anthropological significance of the pterion in the primates. Am J Phys Anthropol. 1933; 18(2): 159-336, doi: 10.1002/ajpa.1330180216.

9. Bellary SS, Steinberg A, Mirzayan N, et al. Wormian bones: a review. Clin Anat. 2013; 26(8): 922-927, doi: 10.1002/ ca.22262, indexed in Pubmed: 23959948.

10. Bhargavi C, Saralaya V, Saralaya V, et al. Pterion: a site for neurosurgical approach. Int J Biomed Res. 2012; 2(12), doi: 10.7439/ijbr.v2i12.207.

11. Broek A. On pteric sutures and pteric bones in the human skull. Kon Acad Wetenesch Amsterdam. Proc Sect Sci. 1914; 6: 634-639.

12. Cheng WY, Lee HT, Sun MH, et al. A pterion keyhole approach for the treatment of anterior circulation aneurysms. Minim Invasive Neurosurg. 2006; 49(5): 257-262, doi: 10.1055/s-2006-954575, indexed in Pubmed: 17163337.

13. Eboh $D$, Obaroefe M. Morphometric study of pterion in dry human skull bones of nigerians. Int J Morphol. 2014; 32(1): 208-213, doi: 10.4067/s0717-95022014000100035.

14. Ersoy M, Evliyaoglu C, Bozkurt MC, et al. Epipteric bones in the pterion may be a surgical pitfall. Minim Invasive Neurosurg. 2003; 46(6): 363-365, doi: 10.1055/s-2003812434, indexed in Pubmed: 14968406. 
15. Fahlbusch R, Schott W. Pterional surgery of meningiomas of the tuberculum sellae and planum sphenoidale: surgical results with special consideration of ophthalmological and endocrinological outcomes. J Neurosurg. 2002; 96(2): 235-243, doi: 10.3171/jns.2002.96.2.0235, indexed in Pubmed: 11838796.

16. Feng Wf, Qi St, Huang Sp, et al. [Surgical treatment of anterior circulation aneurysm via pterion keyhole approach]. Di Yi Jun Yi Da Xue Xue Bao. 2005; 25(12): 1546-1551, indexed in Pubmed: 16361160.

17. Figueiredo EG, Deshmukh P, Nakaji $P$, et al. The minipterional craniotomy: technical description and anatomic assessment. Neurosurgery. 2007; 61 (5 Suppl 2): 256-64; discussion 264, doi: 10.1227/01.neu.0000303978.11752.45, indexed in Pubmed: 18091240.

18. Havaldar P, B.N S, Saheb S, et al. Morphological study on shapes of pterion. Int J Anat Res. 2015; 3(4): 1555-1558, doi: 10.16965/ijar.2015.279.

19. Hendricks BK, Spetzler RF. Pterional craniotomy for anterior temporal artery to middle cerebral artery bypass: 2-dimensional operative video. Oper Neurosurg (Hagerstown). 2020; 19(1): E43, doi: 10.1093/ons/opaa053, indexed in Pubmed: 32171008.

20. Hussain-Saheb S, Haseena S, Prasanna LC. Unusual wormian bones at pterion-three case reports. J Biomed Sci Res. 2010; 2(2): 116-118.

21. Ikeda T, Nakamura M, Itoh M. Sex differences in the zygomatic angle in japanese patients analyzed by MRI with reference to Moiré fringe patterns. Aesthetic Plast Surg. 1999; 23(5): 349-353, doi: 10.1007/s002669900297, indexed in Pubmed: 10541849.

22. Ilknur A, Mustafa K, Sinan B. A comparative study of variation of the pterion of human skulls from 13th and 20th century anatolia. Int J Morphol. 2009; 27(4), doi: 10.4067/s0717-95022009000400051.

23. Kalthur S, Vangara S, Kiruba L, et al. Metrical and non-metrical study of the pterion in South Indian adult dry skulls with notes on its clinical importance. Marmara Med J. 2017; 30(1): 30-30, doi: 10.5472/marumj. 299387.

24. Khatri CR, Gupta DS, Soni DJS. Study of pterion and incidence of epipteric bones in dry human skulls of Gujarat. NJIRM. 2012; 3(2): 57-60.

25. Kumar S, Anurag A, Munjal S, et al. Pterion its location and clinical implications: a study compared. J Evol Med Dent Sci. 2013; 2(25): 4599-4608, doi: 10.14260/jemds/885.

26. Lee $U$, Park D, Kwon $S$, et al. Morphological analysis of the pterion in Korean. J Phys Anthropol. 2001; 14(4): 281, doi: 10.11637/kjpa.2001.14.4.281.

27. Liu Q, Rhoton A. Middle meningeal origin of the ophthalmic artery. Neurosurgery. 2001; 49(2): 401-407, doi: 10.1227/00006123-200108000-00025.

28. Liu YH, Tang Z, Kundu RK, et al. Msx2 gene dosage influences the number of proliferative osteogenic cells in growth centers of the developing murine skull: a possible mechanism for MSX2-mediated craniosynostosis in humans. Dev Biol. 1999; 205(2): 260-274, doi: 10.1006/ dbio.1998.9114, indexed in Pubmed: 9917362.

29. Lovejoy CO, Meindl RS, Mensforth RP, et al. Multifactorial determination of skeletal age at death: a method and blind tests of its accuracy. Am J Phys Anthropol. 1985;
68(1): 1-14, doi: 10.1002/ajpa.1330680102, indexed in Pubmed: 4061595.

30. Ma S, Baillie LM, Stringer MD. Reappraising the surface anatomy of the pterion and its relationship to the middle meningeal artery. Clin Anat. 2012; 25(3): 330-339, doi: 10.1002/ca.21232, indexed in Pubmed: 21800374.

31. Manjunath $K Y$, Thomas IM. Pterion variants and epipteric ossicles in South Indian skulls. J Anat Soc India. 1993; 42: 85-94.

32. Matsumura G, Kida K, Ichikawa R, et al. Pterion and epipteric bones in jpanese adults and fetuses, with special reference to their formation vriations. Kaibogaku Zasshi. 1991; 66(5): 462-471.

33. McLaughlin N, Cutler A, Martin NA. Technical nuances of temporal muscle dissection and reconstruction for the pterional keyhole craniotomy. J Neurosurg. 2013; 118(2): 309-314, doi: 10.3171/2012.10.JNS12161, indexed in Pubmed: 23140151.

34. Mishra A, Mishra P, Bezbaruah N, et al. Study of variations of bony pattern and presence of wormian bone at pterion in dry human skulls. Int J Biomed Res. 2014; 5(11): 668-670, doi: 10.7439/ijbr.v5i11.748.

35. Modasiya UP, Kanani SD. Study of pterion and asterion in adult human skulls of north Gujarat region. Ind J Clin Anat Physiol. 2020; 5(3): 353-356, doi: 10.18231/23942126.2018.0082.

36. Moore KL, Dalley AF. Clinical Oriented Anatomy. 5th ed. Lippincott Williams \& Wilkins, Philadelphia 2006: 887-903.

37. Murphy T. The pterion in the Australian aborigine. Am J Phys Anthropol. 1956; 14(2): 225-244, doi: 10.1002/ ajpa.1330140218, indexed in Pubmed: 13362489.

38. Mwachaka PM, Hassanali J, Odula P. Sutural morphology of the pterion and asterion among adult Kenyans. Braz J Morphol Sci. 2009; 26: 4-7.

39. Natekar P, Natekar S, DeSouza F. Pterion: an anatomical variation and surgical landmark. Ind J Otol. 2011; 17(2): 83, doi: 10.4103/0971-7749.91045.

40. Oguz O, Sanli SG, Bozkir MG, et al. The pterion in Turkish male skulls. Surg Radiol Anat. 2004; 26(3): 220-224, doi: 10.1007/s00276-003-0210-2, indexed in Pubmed: 14648037.

41. Praba AMA, Venkatramaniah C. Morphometric study of different types of Pterion and its relation with middle meningeal artery in dry skulls of Tamil Nadu. JPBMS. 2012; 21(4): 1-4.

42. Prasad H, Bezbaruah NK, Mishra A, et al. Morphometric analysis of pterion: A clinic-anatomical study in north Indian dry skulls. Inn J Med Health Sci. 2015; 5(5): 201-205, doi: 10.15520/ijmhs.2015.vol5.iss5.91..

43. Ranke J. Der Stirnfortsatz der Schlafenschuppe bei den Primaten - Sitz, Mathem. Phys Cl Akad Wiss Munchen. 1898; 27: 227-270.

44. Ruiz C, Souza G, Scherb T, et al. Anatomical variations of pterion: analysis of the possible anatomical variations of pterion in human skulls. J Morphol Sci. 2018; 33(04): 200-204, doi: 10.4322/jms.094615.

45. Sanchez-Lara PA, Graham JM, Hing AV, et al. The morphogenesis of wormian bones: a study of craniosynostosis and purposeful cranial deformation. Am J Med Genet Part A. 2007; 143A(24): 3243-3251, doi: 10.1002/ajmg.a.32073, indexed in Pubmed: 18000970. 
46. Saxena RC, Bilodi AKS, Mane SS, et al. Study of pterion in skulls of Awadh area - in and around Lucknow. Kathmandu Univ Med J (KUMJ). 2003; 1(1): 32-33, indexed in Pubmed: 16340258.

47. Saxena SK, Jain SP, Chowdhary DS. A comparative study of pterion formation and its variations in the skulls of $\mathrm{Ni}$ gerians and Indians. Anthropol Anz. 1988; 46(1): 75-82, indexed in Pubmed: 3389768.

48. Shima K, Kawasaki T, Shimizu A, et al. An Ophthalmic Artery Occlusion after a Craniotomy Using the Pterional Approach : A Report of Three Cases, One resulting in Blindness. Jpn J Neurosurg. 1995; 4(2): 163-169, doi: 10.7887/jens.4.163.

49. Shimizu S, Hagiwara $H$, Utsuki S, et al. Bony tunnel formation in the middle meningeal groove: an anatomic study for safer pterional craniotomy. Minim Invasive Neurosurg. 2008; 51(6): 329-332, doi: 10.1055/s-0028-1085430, indexed in Pubmed: 19061142.

50. Standring S, Ellis H, Healy JC, Johnson D. Gray's anatomy, 39th ed. Elsevier Churchill Livingstone, London 2005: 442-471.

51. Sudha R, Sridevi C, Ezhilarasi M. Anatomical variations in the formation of pterion and asterion in south Indian population. Int J Cur Res Rev. 2013; 5(09): 92-101.

52. Turazzi S, Cristofori L, Gambin R, et al. The pterional approach for the microsurgical removal of olfactory groove meningiomas. Neurosurgery. 1999; 45(4): 821-5; discussion 825, doi: 10.1097/00006123-199910000-00016, indexed in Pubmed: 10515476.

53. Ukoha U, Oranusi CK, Okafor Jl, et al. Anatomic study of the pterion in Nigerian dry human skulls. Niger J Clin Pract.
2013; 16(3): 325-328, doi: 10.4103/1119-3077.113455, indexed in Pubmed: 23771454.

54. Vasudha TK, Divya Shanthi D, Sadashivana G, et al. Study of morphology of pterion and its clinical implications. Int J Anat Res. 2017; 5(4.3): 4674-4678, doi: 10.16965/ ijar.2017.434.

55. Wang Q, Opperman LA, Havil LM, et al. Inheritance of sutural pattern at the pterion in Rhesus Monkey skulls. Anat Rec Discov Mol Cell Evol Biol. 2006; 288: 1042-1049.

56. Williams L, Bannister L, Berry M, Collins P, Dyson M, Dussek E. Gray's anatomy. 38th ed. Churchill Livingston, London 1988.

57. Yasargil M. Interfascial pterional (frontotemporosphenoidal) craniotomy. Microneurosurg. 1984; 1: 217-220.

58. Yasargil M, Fox J, Ray M. The operative approach to aneurysms of the anterior communicating artery. Adv Tech Stand Neurosurg. 1975; 2: 113-170.

59. Yasargil MG, Antic J, Laciga R, et al. Microsurgical pterional approach to aneurysms of the basilar bifurcation. Surg Neurol. 1976; 6(2): 83-91, indexed in Pubmed: 951657.

60. Yaşargil MG, Boehm WB, Ho RE. Microsurgical treatment of cerebral aneurysms at the bifurcation of the internal carotid artery. Acta Neurochir (Wien). 1978; 41(1-3): 61-72, doi: 10.1007/BF01809137, indexed in Pubmed: 665339.

61. Yasargil MG, Fox JL. The microsurgical approach to intracranial aneurysms. Surg Neurol. 1975; 3(1): 7-14, indexed in Pubmed: 1111150.

62. Zalawadia A, Vadgama J, Ruparelia S, et al. Morphometric study of pterion in dry skull of Gujarat Region. NJIRM. 2010; 1(14): 25-29. 